\title{
The medical basis of autism spectrum disorder: Clues for treatment and improving the lives of the entire family
}

\author{
Richard E. Frye* \\ Arkansas Children's Research Institute, Little Rock, AR, USA
}

The incidence of autism spectrum disorder (ASD) has risen at an alarming rate over the last several decades, seeming to have stabilized at a prevalence of almost $2 \%$ of children [1,2]. Although the reason for the dramatic rise continues to be debated, [3] the fact remains that a significant number of children suffer from ASD and that the disability associated with ASD spills over onto the family [4]. Recently, the combined medical, non-medical, and productivity costs has been estimated to be around $\$ 268$ billion annually, exceeding the costs of stroke and hypertension [5].

Despite the fact that decade of research has investigated the basis of ASD, the fact remains that the etiology of ASD remains poorly understood [6]. We previously pointed out that genetic-based research has long dominated the field of ASD research and the number of papers published on the genetics of ASD far outnumbers research papers on other topics [6]. This has been driven in some part by the fact that ASD appears to be highly heritable [7]. However, clinical genetic research has not supported the notion of ASD being caused by Mendelian inherited genetic defects. For example, the 2013 American College of Medical Genetic guidelines estimate that known genetic defects account for a little more than $30 \%$ of cases [8]. Most surprisingly was a recent study that demonstrated a yield of a genetic diagnosis for ASD of just $15.8 \%$ using both chromosomal microarray analysis and whole-exome sequencing [9]. Perhaps more surprising is the fact that a whole-genome sequencing study revealed that the majority of siblings with ASD demonstrate different genetic mutations, thereby suggesting that apparent familial forms of ASD are not driven by simple Mendelian inherited mutations [10]. This is consistent with studies that demonstrate a high rate of de novo mutations, which, for the large part, are not absolutely deleterious by themselves, but involve that mutations in genes connected through interactions of the proteins they produce [11]. This raises the question as to whether genetic mutations have arisen secondary to errors in deoxyribonucleic acid (DNA) maintenance and/or the result of DNA damage due to exposure to extrinsic and/or intrinsic stressors.

A relative large study of twins in California estimated that the environment contributes a greater percent of the risk of developing autistic disorder (58\%) as compared to genetic factors (37\%) [12]. A more recent study from Sweden that included twins, siblings and cousins found a slightly higher genetic contribution $(\sim 50 \%)$ and suggested that the etiology of ASD was most consistent with additive genetic and non-shared environmental effects [7s]. These studies point to the fact that an important piece of the etiology of ASD, the environment, must be included when considering the etiology of ASD. Although environmental research focusing on ASD has been increasing in recent years, [6] a recent review has pointed to the limitations in previous studies and the need for further high-quality studies [13].
Most interestingly, the review pointed to the emerging evidence of the potential interaction between genes associated with ASD and specific environmental toxicants [13]. Of course one exciting consequence of considering the environment in the etiology of ASD is the fact that the environment is a potentially modifiable risk factor that can be manipulated to reduce the incidence of ASD.

Understanding the biological mechanisms of how the environment may cause ASD is important. Several potential physiological mechanisms could translate environmental exposure to adverse biological outcomes including disruption in redox and mitochondrial metabolism as well as dysregulation of the immune system. ${ }^{6}$ For examine glutathione, the body's major intrinsic antioxidant, has been shown to be abnormal in cytosol and mitochondria from cell lines, [14-16] peripheral immune cells, [17] blood [18] and brain tissue [19] derived from children with ASD. Many toxicants biologically cause physiological damage through oxidative stress and these abnormalities in redox metabolism can not only cause damage to proteins, lipids and DNA, but can also cause mitochondrial dysfunction and inflammation $[19,20]$ as well as result in alterations in the transmethylation pathway and DNA methylation [21]. As DNA methylation is essential for epigenetic control of genes, this is a pathway which can silence the gene expression without causing genetic mutations.

Best known for their essential role in the production of adenosine triphosphate (ATP) through oxidative phosphorylation, the mitochondria are also intimately involved in other essential cellular functions such as calcium buffering, redox regulation, apoptosis and inflammation. ATP produced by the mitochondria is essential for a large number of cellular systems. In general, mitochondria sit at the convergence of many of the cell's metabolic pathways where they are thought of as central to the majority of cellular metabolic functions. Thus, abnormal mitochondrial function can affect a large number of cellular systems. Abnormalities in mitochondrial function is being recognized as one of the most prevalent metabolic disorders affecting ASD [22] and many children with ASD manifest symptoms, [23] biomarkers, [22] neuroimaging findings [22] and electron transport chain defects [25] consistent with mitochondrial disease. Interestingly, only about $25 \%$ of those children with ASD and mitochondrial disease have identified genetic abnormalities to account for their mitochondrial disease, [22] suggesting that mitochondrial

Correspondence to: Dr. Richard E. Frye, Slot 512-41B, Room R4041, 13 Children's Way, Little Rock, AR 72202, USA; Tel: 501-364-4662; Fax: 501-3641648; E-mail: REFrye@uams.edu

Received: August 03, 2016; Accepted: August 20, 2016; Published: August 25, 2016 
dysfunction could be secondary to other unknown cellular metabolic defects or due to damage from environmental agents. Indeed many of the same environmental agents that have been linked to autism, such as heavy metal, [13] pesticides [22] and iatrogenic medications such as acetaminophen, [26-29] have also been linked to mitochondrial dysfunction.

Still, we can think of environmental influences in a boarder sense. One of the most influential environments a child experiences is the intrauterine environment during gestation. More and more evidence is accumulating that the maternal environment is important in the development of childhood diseases, particularly ASD. One of the most compelling findings is maternal antibodies to fetal brain proteins. Mothers with particular combinations of these antibodies have offspring with ASD that may have a severe phenotype [30] and more extreme brain enlargement [30] as compared to others with ASD. Still others have provided data that points to the critical role of folate during gestation and around the time of conception in protecting from the development of ASD [32-34] and a recent rodent study suggests that folate receptor alpha autoantibodies, autoantibodies that have been found in both children with ASD and their parents, [35] may have a role disrupting folate metabolism during pregnancy [36]. Other research has pointed to the fact that a genetic polymorphism in the reduced folate carrier in mothers increases the risk of ASD in the offspring [37]. Any disruption in folate metabolism can alter methylation at a critical time during the pre-implantation stages of embryo development, resulting in devastating change to the embryo [38]. These provide examples of the importance of the maternal environment in the development of ASD and provide other examples of pathways toward interventions that may prevent the development of ASD.

Another important environmental factor is the microbiome, the trillions of microorganisms that live on our bodies. These microorganisms can have influence our immune system and influence metabolism. There is growing evidence that children with ASD have imbalances in the enteric microbiome [39]. The microbiome is being increasing recognized as involved in the development of many childhood diseases including ASD, allergic disease and obesity [40]. Interestingly, once thought as sterile, it is being revealed that the prenatal environment has its own microbiome [41,42] suggesting that the maternal microbiome during pregnancy can affect childhood health [42]. The microbiome is established within the first two years of life [43] and preliminary data suggests that probiotics are most useful in preventing childhood disease when given during gestation or early in life [44]. As there is some evidence that microbiome disturbances could be linked to metabolic abnormalities associated with ASD, $[45,46]$ manipulation of the microbiome could be an promising focus of ASD treatment [39].

A better understanding of the etiology of ASD can lead to the developed of treatments that target underlying pathophysiology associated with ASD as well as core and associated ASD symptoms. We recently reviewed some of the evidence for pathophysiology associated with ASD and the evidence for potential treatments [47]. It is important to recognize that considering the underlying pathophysiology of ASD is critical to developing better treatments. Failure to appreciate this fact had led to the misdirection in drug development. For example, Selective Serotonin Reuptake Inhibitors showed promising results on adults with ASD in initial studies but they could not be shown to have efficacy in the target childhood ASD population [48] his reflects differences in the pathophysiological processes believed to underlying well studied psychiatric diseases and the unique nature of ASD.
Developing treatments that target underlying pathophysiology can also steer research to developing disease modifying treatments rather than symptomatic treatments. For example, the only Food and Drug Administration (FDA) approved treatments for ASD are atypical antipsychotic medications which are indicated associated, not core, ASD symptoms. These medications do not appear to be disease modifying but rather are associated with adverse cardiometabolic effect within a short time period (i.e., < 3 months) [49] and increase the risk for developing Type II Diabetes in children [50]. Subjecting children to the development of such adverse health risk factors can certain result in complicated medical management as they grow older into adulthood. Thus, there is an urgent need for drug development for children with ASD, as there currently are no FDA approved medical treatments for ASD that targets the core symptoms of ASD or corrects underlying physiological abnormalities.

Treatments that target underlying pathophysiological processes might not only alleviate ASD symptoms but may improve the lives of individuals with ASD by improving or preventing the development of comorbid disease. An interesting recent study from Sweden demonstrated substantially higher mortality rates (2.6 times higher) in individuals with ASD as compared to matched controls with lower functioning individuals with ASD having higher mortality rates than higher functioning individuals with ASD [51]. Although this was recently verified in a Danish study, [52] the Danish study primarily found evidence for neurologic and psychiatric comorbidities as a cause for higher mortality. As others have pointed out, there is a high rate of mortality associated with epilepsy in ASD, [53] providing an example of how comorbid conditions substantially impact the lives of individuals with ASD. Although the study from Sweden did indeed confirm previous studies demonstrating the substantial higher mortality rate from neurologic and psychiatric disease in ASD, especially in lower functioning individuals, it did demonstrate higher mortality rates due to other diseases including neoplasm, endocrine disease, cardiovascular, respiratory, digestive and genitourinary systems and congenital malformations [51]. Most importantly the recent study from Sweden showed the excess mortality due to suicide in higher functioning individuals with ASD, thereby highlighting potentially poorly controlled or undertreated or poorly recognized psychiatric problems in these individuals.

Thus, ASD is a complicated disorder with morbidity that spreads beyond the core behavioral symptoms which define it. Examining ASD from a biological perspective may give us insights into the treatments and prevention strategies. It is most important to consider that individuals with ASD have complicated biology that can manifest in many disease processes beyond neurologic and psychiatric disease that can cause distress and reduce quality of life and increase morbidity. Gastrointestinal [54,55] and sleep [4] disorders are two for the most obvious but other disorders such as immune, atopic and nutritional disorders can also substantially effect children with ASD [47]. This strongly argues for a multispecialty approach to evaluate and treat children with ASD in order to improve quality of life and decrease morbidity and mortality.

It is also important to appreciate that ASD is not a disease that is isolated to an individuals. Children with ASD need substantial support from their family as well as the educational and medical system. The fact that full-time behavioral therapy is recommended as the standard of care for children with ASD, demonstrates the load on the education and health systems. However, we must factor in the fact that many times at least one parent in consumed with coordinating, advocating 
and caring for a child with ASD. In this sense ASD no longer affects 1 in 68 children, but 3 or more times that many individuals. We recently demonstrated the spillover effect in terms of comorbidities in sleep disturbances [4]. Improving sleep onset with melatonin [56] and behavioral modification can improve the quality of life of both the parent and the child. So, even simply interventions can have a substantial impact of the whole family.

Thus, it is time to take a more integrated approach to managing complex childhood diseases like ASD. Innovation is needed to integrate care for complex children and their families. Understanding the pathophysiology of ASD will lead to the development of more effective treatments and potentially even prevention strategies. Complete care to treat and prevent ASD will require the cooperation and coordination of multiple pediatric specialties as well as obstetricians and internal medicine specialists, potentially rivalling the current model of medical care.

\section{Conflict of interest}

The author has no conflicts of interests to declare.

\section{Acknowledgements}

This work was supported in part by the Arkansas Biosciences Institute.

\section{References}

1. Christensen DL, Baio J, Braun KV, Bilder D, Charles J, et al. (2016) Prevalence and Characteristics of Autism Spectrum Disorder Among Children Aged 8 Years - Autism and Developmental Disabilities Monitoring Network, 11 Sites, United States, 2012. Morbidity and mortality weekly report. Surveillance summaries (Washington, D.C, 2002) $65: 1-23$.

2. Zablotsky B, Black LI, Maenner MJ, Schieve LA, Blumberg SJ, et al. (2015) Estimated Prevalence of Autism and Other Developmental Disabilities Following Questionnaire Changes in the 2014 National Health Interview Survey. National Health Statistics Reports 87: 1-20.

3. Simonoff E (2012) Autism spectrum disorder: prevalence and cause may be bound together. The British Journal of Psychiatry: The Journal of Mental Science 201: 88-89.

4. Tilford JM,, Payakachat N, Kuhlthau KA,, et al. (2015) Treatment for Sleep Problems in Children with Autism and Caregiver Spillover Effects. J Autism Dev Disord 45: 3613-3623. [Crossref]

5. Leigh JP, Du J (2015) Brief Report: Forecasting the Economic Burden of Autism in 2015 and 2025 in the United States. J Autism Dev Disord 45: 4135-4139. [Crossref]

6. Rossignol DA, Frye RE (2012) A review of research trends in physiological abnormalities in autism spectrum disorders: immune dysregulation, inflammation, oxidative stress, mitochondrial dysfunction and environmental toxicant exposures. Molecular Psychiatry 17: 389-401.

7. Sandin S, Lichtenstein P, Kuja-Halkola R, Larsson H, Hultman CM, et al. (2014) The familial risk of autism. JAMA 311: 1770-1777. [Crossref]

8. Schaefer GB, Mendelsohn NJ (2013) Clinical genetics evaluation in identifying the etiology of autism spectrum disorders: 2013 guideline revisions. Genetics in Medicine: Official Journal of the American College of Medical Genetics 15: 399-407.

9. Tammimies K, Marshall CR, Walker S, Kaur G, Thiruvahindrapuram B, et al. (2015) Molecular Diagnostic Yield of Chromosomal Microarray Analysis and Whole-Exome Sequencing in Children With Autism Spectrum Disorder. JAMA 314: 895-903. [Crossref]

10. Yuen RK, Thiruvahindrapuram B, Merico D, Walker S, Tammimies K, et al. (2015) Whole-genome sequencing of quartet families with autism spectrum disorder. Nature Medicine 21: 185-191.

11. Neale BM, Kou Y, Liu L, Ma'ayan A, Samocha KE, et al. (2012) Patterns and rates of exonic de novo mutations in autism spectrum disorders. Nature 485: 242-245. [Crossref]

12. Hallmayer J, Cleveland S, Torres A, Phillips J, Cohen B, et al. (2011) Genetic heritability and shared environmental factors among twin pairs with autism. Arch Gen
Psychiatry 68: 1095-1102. [Crossref]

13. Rossignol DA, Genuis SJ, Frye RE (2014) Environmental toxicants and autism spectrum disorders: a systematic review. Transl Psychiatry 4: e360. [Crossref]

14. James SJ, Rose S, Melnyk S, Jernigan S, Blossom S, et al. (2009) Cellular and mitochondrial glutathione redox imbalance in lymphoblastoid cells derived from children with autism. FASEB journal: official publication of the Federation of American Societies for Experimental Biology. 23: 2374-2383.

15. Rose S, Frye RE, Slattery J, Wynne R, Tippett M, et al. (2014) Oxidative stress induces mitochondrial dysfunction in a subset of autistic lymphoblastoid cell lines. Translational Psychiatry 4: e377.

16. Rose S, Frye RE, Slattery J, Wynne R, Tippett M, et al. (2014) Oxidative stress induces mitochondrial dysfunction in a subset of autism lymphoblastoid cell lines in a wellmatched case control cohort. PloS One 9: e85436.

17. Rose S, Melnyk S, Trusty TA, Pavliv O, Seidel L, et al. (2012) Intracellular and extracellular redox status and free radical generation in primary immune cells from children with autism. Autism Res Treat 2012: 986519. [Crossref]

18. Melnyk S, Fuchs GJ, Schulz E, Lopez M, Kahler SG, et al. (2012) Metabolic imbalance associated with methylation dysregulation and oxidative damage in children with autism. Journal of Autism and Developmental Disorders 42: 367-377.

19. Rose S, Melnyk S, Pavliv O, Bai S, Nick TG, et al. (2012) Evidence of oxidative damage and inflammation associated with low glutathione redox status in the autism brain. Translational psychiatry 2: e134.

20. Rossignol DA, Frye RE (2014) Evidence linking oxidative stress, mitochondrial dysfunction, and inflammation in the brain of individuals with autism. Front Physiol 5: 150. [Crossref]

21. James SJ, Melnyk S, Jernigan S, Hubanks A, Rose S, et al. (2008) Abnormal Transmethylation/transsulfuration Metabolism and DNA Hypomethylation Among Parents of Children with Autism. J Autism Dev Disord 38: 1976. [Crossref]

22. Rossignol DA, Frye RE (2012) Mitochondrial dysfunction in autism spectrum disorders a systematic review and meta-analysis. Mol Psychiatry 17: 290-314. [Crossref]

23. Frye RE, Rossignol DA (2011) Mitochondrial dysfunction can connect the diverse medical symptoms associated with autism spectrum disorders. Pediatric Research 69: $41 \mathrm{r}-47 \mathrm{r}$.

24. Goh S, Dong Z, Zhang Y, DiMauro S, Peterson BS (2014) Mitochondrial dysfunction as a neurobiological subtype of autism spectrum disorder: evidence from brain imaging. JAMA Psychiatry 71: 665-671. [Crossref]

25. Giulivi C, Zhang YF, Omanska-Klusek A, Ross-Inta C, Wong S, et al. (2010) Mitochondrial dysfunction in autism. JAMA 304: 2389-2396. [Crossref]

26. Andrade C (2016) Use of acetaminophen (paracetamol) during pregnancy and the risk of autism spectrum disorder in the offspring. The Journal of Clinical Psychiatry 77: e152-154.

27. Bauer AZ, Kriebel D (2013) Prenatal and perinatal analgesic exposure and autism: an ecological link. Environ Health 12: 41. [Crossref]

28. Liew Z, Ritz B, Virk J, Olsen J (2015) Maternal use of acetaminophen during pregnancy and risk of autism spectrum disorders in childhood: A Danish national birth cohort study. Autism Research: Official Journal of the International Society for Autism Research. Dec 21.

29. Avella-Garcia CB, Julvez J, Fortuny J, Rebordosa C, Garcia-Esteban R, et al. (2016) Acetaminophen use in pregnancy and neurodevelopment: attention function and autism spectrum symptoms. International Journal of Epidemiology. Jun 28.

30. Piras IS, Haapanen L, Napolioni V, Sacco R, Van de Water J, et al. (2014) Anti-brain antibodies are associated with more severe cognitive and behavioral profiles in Italian children with Autism Spectrum Disorder. Brain Behav Immun 38: 91-99. [Crossref]

31. Nordahl CW, Braunschweig D, Iosif AM, Lee A, Rogers S, Ashwood P, et al. (2013) Maternal autoantibodies are associated with abnormal brain enlargement in a subgroup of children with autism spectrum disorder. Brain, Behavior, and Immunity 30: 61-65.

32. Steenweg-de Graaff J, Ghassabian A, Jaddoe VW, Tiemeier H, Roza SJ (2015) Folate concentrations during pregnancy and autistic traits in the offspring. The Generation $\mathrm{R}$ Study. Eur J Public Health 25: 431-433. [Crossref]

33. Suren P, Roth C, Bresnahan M, Haugen M, Hornig M, et al. (2013) Association between maternal use of folic acid supplements and risk of autism spectrum disorders in children. JAMA 309: 570-577.

34. Schmidt RJ, Tancredi DJ, Ozonoff S, Hansen RL, Hartiala J, et al. (2012) Maternal 
periconceptional folic acid intake and risk of autism spectrum disorders and developmental delay in the CHARGE (CHildhood Autism Risks from Genetics and Environment) case-control study. Am J Clin Nutr 96: 80-89. [Crossref]

35. Frye RE, Sequeira JM, Quadros EV, James SJ, Rossignol DA (2013) Cerebral folate receptor autoantibodies in autism spectrum disorder. Mol Psychiatry 18: 369-381. [Crossref]

36. Sequeira JM, Desai A, Berrocal-Zaragoza MI, Murphy MM, et al. (2016) Exposure to Folate Receptor Alpha Antibodies during Gestation and Weaning Leads to Severe Behavioral Deficits in Rats: A Pilot Study. PloS One 11: e0152249.

37. James SJ, Melnyk S, Jernigan S, Pavliv O, Trusty T, et al. (2010) A functional polymorphism in the reduced folate carrier gene and DNA hypomethylation in mothers of children with autism. American journal of medical genetics. Part B, Neuropsychiatric genetics: the official publication of the International Society of Psychiatric Genetics 153: $1209-1220$.

38. Menezo YJ, Elder K, Dale B (2015) Link between increased prevalence of autism spectrum disorder syndromes and oxidative stress, DNA methylation, and imprinting: the impact of the environment. JAMA Pediatrics 169: 1066-1067.

39. Frye RE, Slattery J, MacFabe DF, Allen-Vercoe E, Parker W, et al. (2015) Approaches to studying and manipulating the enteric microbiome to improve autism symptoms. Microbial Ecology in Health and Disease 26: 268-278.

40. O'Mahony SM,, Stilling RM, Dinan TG,, et al. (2015) The microbiome and childhood diseases: Focus on brain-gut axis. Birth Defects Res C Embryo Today 105: 296-313. [Crossref]

41. Aagaard K, Ma J, Antony KM, Ganu R, Petrosino J, et al. (2014) The placenta harbors a unique microbiome. Sci Transl Med 6: 237ra65. [Crossref]

42. Ardissone AN, de la Cruz DM, Davis-Richardson AG, Rechcigl KT, Li N, et al. (2014) Meconium microbiome analysis identifies bacteria correlated with premature birth PloS One 9: e90784.

43. de Meij TG, Budding AE, de Groot EF, Jansen FM, Frank Kneepkens CM, et al. (2016) Composition and stability of intestinal microbiota of healthy children within a Dutch population. FASEB Journal: official publication of the Federation of American Societies for Experimental Biology 30: 1512-1522.

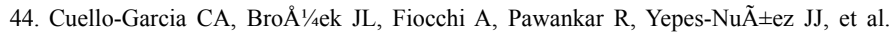
(2015) Probiotics for the prevention of allergy: A systematic review and meta-analysis of randomized controlled trials. J Allergy Clin Immunol 136: 952-961. [Crossref]
45. Frye RE, Melnyk S, Macfabe DF (2013) Unique acyl-carnitine profiles are potential biomarkers for acquired mitochondrial disease in autism spectrum disorder Translational Psychiatry 3: e220.

46. Frye RE, Rose S, Slattery J, et al. (2015) Gastrointestinal dysfunction in autism spectrum disorder: the role of the mitochondria and the enteric microbiome. Microb Ecol Health Dis 26: 274-258. [Crossref]

47. Frye RE, Rossignol DA (2016) Identification and Treatment of Pathophysiological Comorbidities of Autism Spectrum Disorder to Achieve Optimal Outcomes. Clinical Medicine Insights Pediatrics 10: 43-56.

48. Williams K, Brignell A, Randall M, Silove N, Hazell P (2013) Selective serotonin reuptake inhibitors (SSRIs) for autism spectrum disorders (ASD). Cochrane Database Syst Rev: CD004677. [Crossref]

49. Correll CU, Manu P, Olshanskiy V, Napolitano B, Kane JM, et al. (2009) Cardiometabolic risk of second-generation antipsychotic medications during first-time use in children and adolescents. JAMA 302: 1765-1773. [Crossref]

50. Galling B, Roldan A, Nielsen RE, Nielsen J, Gerhard T, et al. (2016) Type 2 Diabetes Mellitus in Youth Exposed to Antipsychotics: A Systematic Review and Meta-analysis. JAMA Psychiatry 73: 247-259.

51. Hirvikoski T, Mittendorfer-Rutz E, Boman M, Larsson H, Lichtenstein P, et al. (2016) Premature mortality in autism spectrum disorder. Br J Psychiatry 208: 232-238. [Crossref]

52. Schendel DE, Overgaard M, Christensen J, Hjort L, Jorgensen M, et al. (2016) Association of Psychiatric and Neurologic Comorbidity With Mortality Among Persons With Autism Spectrum Disorder in a Danish Population. JAMA Pediatrics 170: $243-250$

53. Pickett J, Xiu E, Tuchman R, Dawson G, Lajonchere C (2011) Mortality in individuals with autism, with and without epilepsy. J Child Neurol 26: 932-939. [Crossref]

54. Buie T, Campbell DB, Fuchs GJ, Furuta GT, Levy J, et al. (2010) Evaluation, diagnosis, and treatment of gastrointestinal disorders in individuals with ASDs: a consensus report. Pediatrics 125 Suppl 1:S1-18.

55. Buie T, Fuchs GJ, Furuta GT, Kooros K, Levy J, et al. (2010) Recommendations for evaluation and treatment of common gastrointestinal problems in children with ASDs. Pediatrics 125 Suppl 1: S19-29.

56. Rossignol DA, Frye RE (2011) Melatonin in autism spectrum disorders: a systematic review and meta-analysis. Dev Med Child Neurol 53: 783-792. [Crossref]

Copyright: (C2016 Frye RE. This is an open-access article distributed under the terms of the Creative Commons Attribution License, which permits unrestricted use, distribution, and reproduction in any medium, provided the original author and source are credited. 